\title{
Transformation of silver nanoparticles released from skin cream and mouth spray in artificial sweat and saliva solutions: particle size, dissolution, and surface area
}

\author{
Jonas Hedberg $^{1}$ (D) Madeleine Eriksson $^{1} \cdot$ Amina Kesraoui $^{1} \cdot$ Alexander Norén $^{1} \cdot$ Inger Odnevall Wallinder $^{1}$ (D)
}

Received: 31 March 2020 / Accepted: 12 October 2020 / Published online: 23 October 2020

(C) The Author(s) 2020

\begin{abstract}
The use of silver nanoparticles (Ag NPs) in consumer products can result in diffuse environmental dispersion of both NPs and ionic silver. This study investigated the transformation of Ag NPs present in two consumer products (skin cream, mouth spray) in terms of release of Ag NPs and ionic silver and changes in particle size in artificial sweat and saliva solutions. Large differences in silver release were observed with the smaller sized Ag NPs in mouth spray releasing more silver compared with the Ag NPs of the skin cream. Substantial particle agglomeration took place in both artificial sweat and saliva, forming large-sized agglomerates (> $100 \mathrm{~nm}$ ). The amount of dissolved silver in solution after $24 \mathrm{~h}$ was less than $10 \%$ of the total amount of Ag NPs for both products. The results show that the Ag NPs of these consumer products will largely remain as NPs even after $24 \mathrm{~h}$ of skin or saliva contact. The use of normalization by geometric surface area of the particles was tested as a way to compare dissolution for Ag NPs of different characteristics, including pristine, bare, as well as PVP-capped Ag NPs. Normalization of silver dissolution with the geometric surface area was shown promising, but more extensive studies are required to unambiguously conclude whether it is a way forward to enable grouping of the dissolution behavior of Ag NPs released from consumer products.
\end{abstract}

Keywords Silver nanoparticles $\cdot$ Consumer products $\cdot$ Dissolution $\cdot$ Sweat $\cdot$ Saliva $\cdot$ Particle size

\section{Introduction}

Silver nanoparticles (Ag NPs) are used in a large variety of consumer products (Hansen et al. 2016; Vance et al. 2015), mainly to provide antimicrobial effects (Zhang et al. 2016). Silver can be released as Ag NPs and/or ions from such consumer products and interact with humans and the environment. This release has spurred numerous investigations on transformations of Ag NPs upon dispersion, including aspects such as surface chemistry, dissolution, and toxicity (Cronholm

Responsible editor: Philippe Garrigues

Electronic supplementary material The online version of this article (https://doi.org/10.1007/s11356-020-11241-w) contains supplementary material, which is available to authorized users.

Jonas Hedberg

jhed@kth.se

1 KTH Royal Institute of Technology, School of Engineering Sciences in Chemistry, Biotechnology and Health, Department of Chemistry, Division of Surface and Corrosion Science, Stockholm, Sweden et al. 2013; Hedberg et al. 2019a; Levard et al. 2013a; Levard et al. 2012; Levard et al. 2013b; Zhang et al. 2016). The toxic potency and the physico-chemical properties of the Ag NPs govern possible hazards on human health and the environment, combined with the actual dose (concentration) of dispersed Ag NPs (Arvidsson et al. 2011; Benn and Westerhoff 2008; Coll et al. 2016; Gunawan et al. 2017; Zhang et al. 2016).

The regulatory framework is trying to catch up with the rapid development and use of new nanomaterials (NM), including Ag NPs, to ensure their safe and sustainable use and handling. In 2018 the Swedish Chemicals Agency (KemI), for example, implemented a rule that producers of NMcontaining products must register properties (e.g., size and charge) of added NMs (Kemikalieinspektionen 2015). However, this database and other collections of data on NMs largely lack information on actual release rates of $\mathrm{Ag}$ NPs from such products (Hansen et al. 2016), as well as on properties of released NMs (size, composition, morphology, etc.) (Koivisto et al. 2017). This shortage of data is also evident from the scientific literature for which most studies that addresses the release of NMs from consumer products $(67 \%$ 
as of 2016) do not include any information on NM transformation products (Caballero-Guzman and Nowack 2016). The need for more real-world realistic test systems has moreover been recognized (Mitrano et al. 2015b; Mitrano and Nowack 2017)

Ag NP-containing consumer products are among the most studied NM-containing products. Available studies include transformation information of Ag NPs during simulated exposure scenarios of, e.g., socks (Benn and Westerhoff 2008), toothbrushes (Mackevica et al. 2017), food containers (Mackevica et al. 2016), dietary supplements (Radwan et al. 2019), surface sanitizers (Radwan et al. 2019), mouth sprays (Quadros and Marr 2011), fabrics (Kulthong et al. 2010), and various products for children (Quadros et al. 2013; Tulve et al. 2015). Pristine Ag NPs as model systems for Ag NPs released from consumer products have been studied to understand possible transformations and environmental interactions. These investigations include, for example, interactions with laundry cycle component and surface water (Hedberg et al. 2014b), as well as the influence of light on Ag NP aging (Mitrano et al. 2015a). Some studies report extensive agglomeration of $\mathrm{Ag}$ NP in artificial saliva (Lin-Vien et al. 1991), whereas others report reduced agglomeration in authentic saliva due to the presence of organic compounds (Ngamchuea et al. 2018). The presence of capping agents/adsorbed ligands on Ag NPs has shown to influence their stability, as illustrated by, for example, a reduced extent of particle agglomeration and altered chemical stability. These differences in stability can influence dissolution rates and kinetics compared with bare particles (Liu et al. 2018; Molleman and Hiemstra 2017; Radwan et al. 2019). A study that compared Ag NPs in socks with pristine particles showed that a $24 \mathrm{~h}$ incubation of the pristine NPs in wastewater could serve as a model for the behavior of transformed NPs from a consumer product (Mohan et al. 2019). However, as there are several hundreds of different Ag NP-containing consumer products but scarce data on the transformation and characteristics of released Ag NPs, it would be very valuable to simplify and group these products in terms of, for example, their dissolution characteristics. This would speed up investigations on the release and transformation of Ag NPs (e.g., size, dissolution, surface properties) from different consumer products on the market that can be used in modeling of hazards and environmental fate (CaballeroGuzman and Nowack 2016; Mitrano et al. 2015b; Mitrano and Nowack 2017).

This work studies transformation of Ag NPs released from two different consumer products (skin cream, mouth spray) in synthetic sweat and saliva. Ag NPs are added to these kind of products as an antimicrobial agent (Khaksar et al. 2019a), and other personal care products incorporating Ag NPs include, for example, shampoo and toothpaste (Benn et al. 2010) Ag NPs represent a smaller part of the NPs in personal care products, with $\mathrm{TiO}_{2}$ and $\mathrm{ZnO}$ being the most commonly used NPs
(Keller et al. 2014). The release of Ag to graywater (household water) has been identified as an important route for dispersion of $\mathrm{Ag}$ emissions from Ag NPs in personal care products (Khaksar et al. 2019a).

The investigations include quantification of released $\mathrm{Ag}$ NPs and their extent of dissolution into silver ionic species, as well as measurements of surface composition and changes in particle size distribution over a $24 \mathrm{~h}$ time period. The behavior of the Ag NP-containing consumer products and pristine Ag NPs are compared in terms of dissolution normalized by the geometric surface area (based on the primary size of the NPs at dry unexposed conditions). The aim is to contribute with knowledge that elucidates the applicability of using pristine Ag NPs, or reported findings for Ag NPs in consumer products, as models to assess the release of ionic silver from Ag NPs in consumer products. Normalization by geometric surface area is clearly a simplified approach since other properties certainly will influence the dissolution process, such as differences in particle size and presence of capping agents (Hedberg et al. 2019b). The geometrical surface area is on the other hand a parameter which in most cases is readily available, as opposed to, for example, the fractal dimension of agglomerates, effective surface area of particles/ agglomerates in solution, or their surface composition in solution. This study will investigate whether there is a trend between surface area and dissolution and to assess differences between different kinds of Ag NPs. Literature findings on dissolution is compiled together with data generated in this study for Ag NP-containing consumer products and pristine Ag NPs (bare, PVP-capped). Investigations of both capped and bare Ag NPs serve the purpose to represent Ag NPs with significantly different initial surface properties at the starting point of the exposure in the synthetic body fluids of interest.

\section{Materials and methods}

\section{Solutions and chemicals}

Table 1 gives the compositions of artificial sweat (ASW) and artificial saliva (AS), using ultrapure water $(18.2 \mathrm{M} \Omega \mathrm{cm}$ resistivity, Millipore, Solna, Sweden) as solvent.

All chemicals were of analytical grade (p.a.) or puriss. The glassware was immersed in $10 \% \mathrm{HNO}_{3}$ for at least $24 \mathrm{~h}$ and thoroughly rinsed with ultrapure water prior to usage.

\section{Silver nanoparticles}

The consumer products were manufactured by MaxLab (Serbia) and marketed under the name "Silversalva" (skin cream containing Ag NPs) and "Silversept munsprej" (mouth spray containing Ag NPs). According to the manufacturer information, the skin cream and the mouth spray contain 30 
Table 1 Chemical composition of artificial sweat and artificial saliva

\begin{tabular}{|c|c|c|}
\hline & $\begin{array}{l}\text { Artificial sweat } \\
\text { (CEN 2011) }\end{array}$ & $\begin{array}{l}\text { Artificial saliva } \\
\text { (Oh and Kim 2005) }\end{array}$ \\
\hline $\mathrm{pH}$ & 6.5 & 6.75 \\
\hline $\mathrm{NaCl}(\mathrm{g} / \mathrm{L})$ & 5.0 & 0.4 \\
\hline Lactic acid (g/L) & 1.0 & - \\
\hline $\mathrm{KCl}(\mathrm{g} / \mathrm{L})$ & - & 0.4 \\
\hline Urea $(\mathrm{g} / \mathrm{L})$ & 1.0 & 1.0 \\
\hline $\mathrm{CaCl}_{2} \cdot \mathrm{H}_{2} \mathrm{O}(\mathrm{g} / \mathrm{L})$ & - & 0.795 \\
\hline $\mathrm{NaH}_{2} \mathrm{PO}_{4} \cdot \mathrm{H}_{2} \mathrm{O}(\mathrm{g} / \mathrm{L})$ & - & 0.78 \\
\hline $\mathrm{Na}_{2} \mathrm{~S} \cdot 9 \mathrm{H}_{2} \mathrm{O}(\mathrm{g} / \mathrm{L})$ & - & 0.005 \\
\hline
\end{tabular}

and $20 \mathrm{mg} \mathrm{Ag} / \mathrm{kg}$ product, respectively. Other ingredients of the skin cream include calendula, allantoin, vitamin B5, and glutamine. Ingredients of the mouth spray were Acacia senegal (a herbal constituent), panthenol, Mentha x piperita oil, Salvia officinalis oil, Pimpinella anisum seed oil, Thymus zygis, and herb oil. Pristine PVP-capped (40 kDa) Ag NPs were purchased from Nanocomposix (San Diego, USA) with a primary size of $50 \mathrm{~nm}$ according to the manufacturer. The bare Ag NPs were purchased from American Elements (Cleveland, USA) in a purity of $99.9 \%$.

\section{Electron microscopy}

Transmission electron microscopy (TEM) imaging of bare and PVP-capped Ag NPs was performed using a Hitachi HT7700 instrument, operating at $100 \mathrm{kV}$. The bare Ag NPs were prepared by dispersing and sonicating (see details elsewhere (Pradhan et al. 2016)) the particles in butyl alcohol at a concentration of $1 \mathrm{~g} / \mathrm{L}$ for $15 \mathrm{~min}$. The suspension was then pipetted onto TEM copper grids coated with Formvar® films (Ted Pella, USA) from which the solvent evaporated under ambient laboratory conditions. The PVP-capped Ag NPs were prepared by placing a drop from the stock solution $(5 \mathrm{~g} / \mathrm{L} \mathrm{Ag}$ NPs) onto the TEM grid. Excess solution was removed using a paper tissue. All TEM images were recorded in bright field mode except for the Ag NPs in the skin cream (dark field mode).

The Ag NPs in the skin cream and the mouth spray were imaged using a JEOL $200 \mathrm{kV}$ 2100F field emission microscope operated in scanning beam mode (STEM). This was combined with energy-dispersive spectroscopy (EDS) microanalysis, using a windowless silicon drift detector X-MaxN TLE from Oxford Instruments and the Aztec Software, to identify the Ag NPs. Samples of the skin cream were prepared by heating the skin cream at $500{ }^{\circ} \mathrm{C}$ for $30 \mathrm{~min}$ in a muffle furnace to reduce its organic matter content. The ash was dispersed in butyl alcohol in a sonication bath for $20 \mathrm{~min}$ before being deposited onto the copper grid followed by solvent evaporation at ambient conditions. The mouth spray was prepared placing a drop of the stock solution on the grid removing excess liquid using a blotting paper.

\section{Dissolution studies}

The Ag NPs were added to the different test solutions in Nalgene $\odot$ jars that were incubated for $20 \mathrm{~min}, 1 \mathrm{~h}$, and $24 \mathrm{~h}$ using a Stuart S180 Platform-rocker incubator (bilinear shaking, 22 cycles per $\min , 12^{\circ}$ inclination). The exposures were conducted at $30^{\circ} \mathrm{C}$ in ASW and at $37^{\circ} \mathrm{C}$ in AS. All Ag NPs were investigated at a particle concentration of $2 \mathrm{mg} / \mathrm{L}$ in a total solution volume of $20 \mathrm{~mL}$. The PVP-capped Ag NPs were diluted directly from the stock suspension.

The bare Ag NPs, initially in dry powder form, were sonicated into a stock solution of $1 \mathrm{~g} \mathrm{Ag} \mathrm{NPs/L}$. Details of the sonication settings and procedure are given elsewhere (Pradhan et al. 2016). In short, the delivered acoustic energy was $1.2 \cdot 10^{6} \mathrm{~J} / \mathrm{L}$ by means of a Branson Sonifier using a micro tip for $15 \mathrm{~min}$. The solution was cooled in an ice bath during the sonication process (Pradhan et al. 2016). The sonicated stock suspension was further diluted to a particle concentration of $2 \mathrm{mg} \mathrm{Ag} \mathrm{NPs/L}$. Both the mouth spray and the skin cream were diluted directly from the product into the Nalgene jars. Three independent replicas were investigated and analyzed for all dissolution studies in ASW and AS.

\section{Quantification of released Ag from the Ag NPs}

From each exposed sample and time point, solution samples were collected and separated into a filtered and a non-filtered sample. Membrane filtration was performed to determine the fraction of released silver ions in solution. The remaining concentrations of Ag NPs in solution after the exposures and time periods were calculated by subtracting this fraction from the total amount of silver in the non-filtered samples. Filtration was made by passing $6 \mathrm{~mL}$ of the sample solution through an alumina filter (20 nm pore size, Anotop filter, Whatman) after which $15 \mu \mathrm{L}$ of $65 \% \mathrm{HNO}_{3}$ was added to preserve the samples $(\mathrm{pH}<2)$ and to dissolve the Ag NPs prior to analyses of the total silver concentration.

Atomic absorption spectroscopy (AAS) was employed to determine the silver ion concentration in solution using a Perkin Elmer AAnalyst 700 instrument in graphite furnace mode. Calibration standards of 7.5, 15, 30, and $45 \mu \mathrm{g} \mathrm{Ag} / \mathrm{L}$ were prepared from a $1 \mathrm{~g} \mathrm{Ag} / \mathrm{L}$ certified standard (Perkin Elmer). Recovery measurements of added Ag ions (of similar concentrations as the calibration standards) in AS and ASW resulted in a $80-90 \%$ recovery. The detection limit, $1.5 \mu \mathrm{g}$ $\mathrm{Ag} / \mathrm{L}$, was estimated from three times the standard deviation of the blank samples. Calibration standards were analyzed every 5 th sample, and re-calibration was performed if the calibration standard deviated more than $10 \%$ from the stipulated value. 


\section{Particle size}

The hydrodynamic particle number distribution was investigated by means of nanoparticle tracking analysis (NTA, Malvern Nanosight NS300, Uppsala, Sweden) using a 405$\mathrm{nm}$ laser and an acquisition time of $60 \mathrm{~s}$, repeated three times. Three independent samples were investigated for each time point. The camera level was intentionally kept very low (camera level 4) in order to target the Ag NPs, thereby excluding information from particles of organic matter present in the mouth spray and the skin cream during the measurements (Mehrabi et al. 2017).

\section{Surface characterization}

A Horiba Yvon Jobin HR800 Raman spectrometer with a laser wavelength of $532 \mathrm{~nm}$ and a 50X objective was used for surface characterization of the Ag NPs in the mouth spray, the PVP-capped Ag NPs, and the bare Ag NPs. No measurements were possible for Ag NPs of the skin cream. Three different spots were investigated for each particle type with the laser beam softly focused to avoid any beam damage. The samples were checked by means of optical microscopy before and after the measurements to assure no laser-induced damage. For the mouth spray, a drop of the spray was deposited onto a glass slide and left to evaporate before the Raman investigation. The measurements were focused on agglomerates of Ag NPs that could be identified through the optical microscope (see Fig. S1 in supporting information) and that resulted in a very large signal owing to the surface-enhanced Raman effect (Moskovits 2005). The PVP-capped Ag NPs were investigated in the stock solution as a drop on a glass slide. The Raman investigations of the bare Ag NPs were conducted on the dry powder.

\section{Zeta potential}

A Zetasizer Nano ZS instrument (Malvern Instruments, UK) was used to estimate the zeta potential of the NPs in ASW and in AS. The measurements were conducted at $25^{\circ} \mathrm{C}$ in triplicate readings. The Smoluchowski approximation was used for modeling of the zeta potential distribution. The PVP-capped $\mathrm{Ag}$ NPs and the mouth spray Ag NPs were diluted in $10 \mathrm{mM}$ $\mathrm{NaCl}$ to a concentration of $0.1 \mathrm{~g} / \mathrm{L} \mathrm{Ag} \mathrm{NPs}$. The measurements were performed in $10 \mathrm{mM} \mathrm{NaCl}$ as the high ionic strength of AS and ASW make zeta potential determinations difficult due to screening of surface charges (Skoglund et al. 2017). The bare Ag NPs were sonicated prior to the measurements; see details elsewhere for sonication settings (Pradhan et al. 2016).

\section{Chemical equilibrium calculations}

Chemical equilibrium calculations of released silver in solution were performed using the Medusa software (Puigdomenech 2001), with the chemical composition of the AS and ASW solutions as input values (detailed in Table 1).

\section{Results and discussion}

\section{Properties of Ag NPs before exposure}

TEM images of the studied Ag NPs and their properties in terms of primary size (from TEM), zeta potential are presented in Fig. 1 and Table 2. Figure 2 shows the results of Raman spectroscopy.

The TEM images of the mouth spray showed Ag NPs sized 2-20 nm, particles that in some cases formed agglomerates (see SEM picture in supporting information Fig. S3, S4). The size of the bare and PVP-capped Ag NPs was larger than those in the mouth spray, with primary sizes between 50 and $150 \mathrm{~nm}$ and $50-70 \mathrm{~nm}$, respectively. The Ag NPs in the skin cream were in the size range of $15-25 \mathrm{~nm}$.

The zeta potential measurements in $10 \mathrm{mM} \mathrm{NaCl}$ showed the bare Ag NPs to be uncharged $(0 \mathrm{mV})$, and both the PVPcapped Ag NPs $(-46 \mathrm{mV})$ and the Ag NPs of the mouth spray $(-24 \mathrm{mV})$ to be negatively charged. No measurements were possible for the Ag NPs of the skin cream.

The composition of surface constituents of the Ag NPs was assessed using Raman spectroscopy (Fig. 2), except for the skin cream that did not give any useful results due to difficulties in finding the Ag NPs in the matrix.

The bare Ag NPs showed the presence of carbonate- and carboxyl-containing compounds as deduced from Raman bands at for example 700,1131, 1392, 1476, and $1607 \mathrm{~cm}^{-1}$ (Fig. 2a) (Kai et al. 1989; McQuillan et al., 1975). Adsorbed silver carbonate has previously been seen to desorb from bare Ag NPs when immersed in solution (Hedberg et al. 2012). A peak at $235 \mathrm{~cm}^{-1}$ indicates the presence of Ag-O species (Kai et al. 1989). Observed Raman bands from the Ag NPs in the mouth spray (Fig. 2b) were more difficult to assign but most likely related to components containing $\mathrm{C}-\mathrm{H}$ (1215, $\left.2931 \mathrm{~cm}^{-1}\right)$, C-C $\left(1550,1586 \mathrm{~cm}^{-1}\right), \mathrm{C}-\mathrm{O}(1153$, $\left.1215 \mathrm{~cm}^{-1}\right)$, and $\mathrm{COO}^{-}$and/or C-N groups $(1315,1365$, $1550,1586 \mathrm{~cm}^{-1}$ ) (Lin-Vien et al. 1991). The Raman spectra of the PVP-capped Ag NPs (Fig. 2c) confirmed the presence of PVP at the surface as judged by Raman bands at 647 , $765 \mathrm{~cm}^{-1}$ (ring torsion, out of plane), $941 \mathrm{~cm}^{-1}$ (CH out of plane bend), and $1362 \mathrm{~cm}^{-1}$ (ring breathing mode) (Mdluli et al. 2009).

The total silver content of the cosmetic products followed a concentration of $31.2 \pm 0.3 \mathrm{mg} \mathrm{Ag} / \mathrm{kg}$ product for the mouth spray and $24.1 \pm 0.4 \mathrm{mg} \mathrm{Ag} / \mathrm{kg}$ product for the skin cream. 
Table 2 Primary particle size (based on TEM measurements), zeta potential, and surface compounds (from Raman measurements) of the investigated Ag NPs

\begin{tabular}{llll}
\hline Ag NPs & Primary size $(\mathrm{nm})$ & Zeta potential $(\mathrm{mV})$ in $10 \mathrm{mM} \mathrm{NaCl}$ & Surface compounds \\
\hline Bare & $50-150$ & 0 & Ag-O, Ag carbonate \\
PVP-capped & $50-70$ & $-46 \pm 2$ & PVP \\
Mouth spray & $2-20$ & $-24 \pm 3$ & Organic compounds \\
Skin cream & $15-25$ & N/A & N/A \\
\hline
\end{tabular}

These concentrations are slightly higher compared with the supplier information (30 and $20 \mathrm{mg} / \mathrm{kg}$, respectively). The measured silver contents of the consumer products were in the range of what has previously been reported for different consumer products, whereas the observed primary sizes of the Ag NPs were in the lower range of earlier observations (Khaksar et al. 2019b; Quadros et al. 2013; Tulve et al. 2015).

Since rapid dissolution already during the preparation of stock solutions has been observed for other metal-containing NPs (Pradhan et al. 2016), such information needs to be reported for any dissolution studies of NPs. For the bare Ag NPs of this study, a very small fraction of silver was dissolved (0.001\%, measured with AAS after filtration through a $20 \mathrm{~nm}$ membrane) after sonication and dilution to the intended particle concentration $(2 \mathrm{mg} / \mathrm{L})$ for exposures in synthetic media. Similar quantities $(0.001 \%)$ of dissolved silver were observed for the PVP-capped Ag NPs (2 mg/L Ag NPs) after dilution into ASW and AS. Higher levels were observed for the Ag NPs in the mouth spray $(0.34 \%)$ for the same particle loading as for the bare and PVP-capped Ag NPs.

\section{Dissolution and particle agglomeration kinetics for $\mathbf{A g}$ NPs in skin cream and mouth spray}

Particle size kinetics are presented in Fig. 3 for Ag NPs released from the skin cream in ASW (a), mouth spray in AS (b), PVP Ag NPs in ASW (c), and AS (d). In all cases, there was no statistical difference between the different time points due to largely varying results between the replicas.

When compared with the primary sizes of the Ag NPs in mouth spray (5-25 nm, Fig. 1c), agglomeration was evident already within $20 \mathrm{~min}$ in AS seen from the polydisperse size distributions with sizes ranging from typically 10 to $800 \mathrm{~nm}$. Similar observations were made for the Ag NPs released from the skin cream (primary sizes 15-25 nm, Fig. 1d) into ASW with a particle size distribution ranging from approximately
Fig. 1 TEM images of bare Ag NPs (a), PVP-capped Ag NPs (b), Ag NPs in mouth spray (c), and Ag NPs in skin cream (d). All images were collected in bright field mode except for the skin cream obtained using dark field mode. EDS measurements confirmed the silver content of the text-marked spots in $\mathbf{d}$. EDS spectra given in Fig. S2 for the $\mathrm{Ag}$ NPs in the mouth spray a

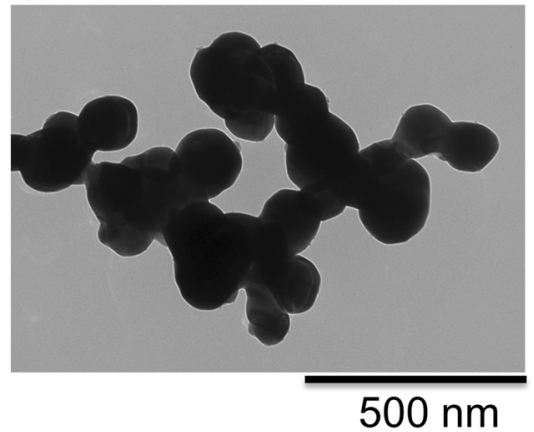

C

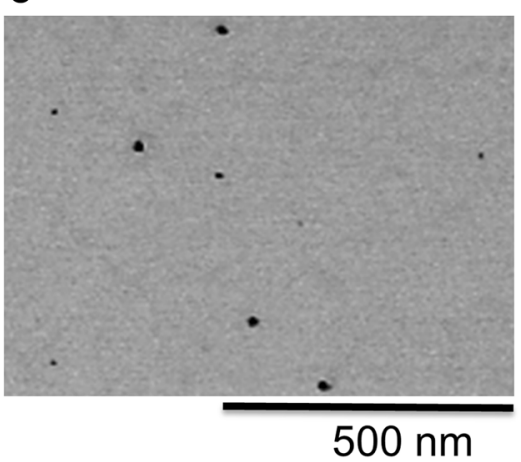

b

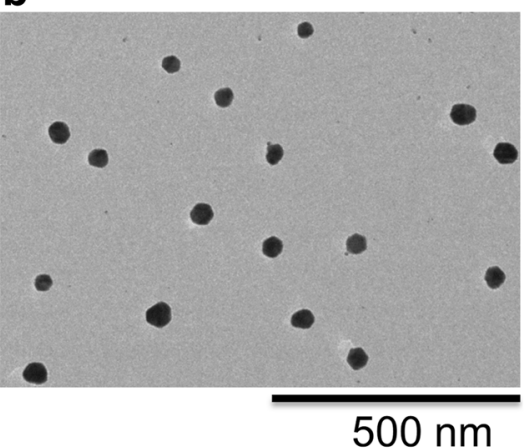

d

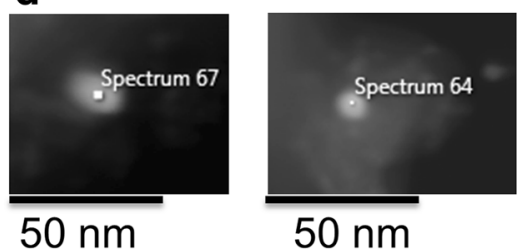


Fig. 2 Raman spectra of Ag NPs. a bare Ag NPs. b Ag NPs in mouth spray. c PVP-capped Ag NPs
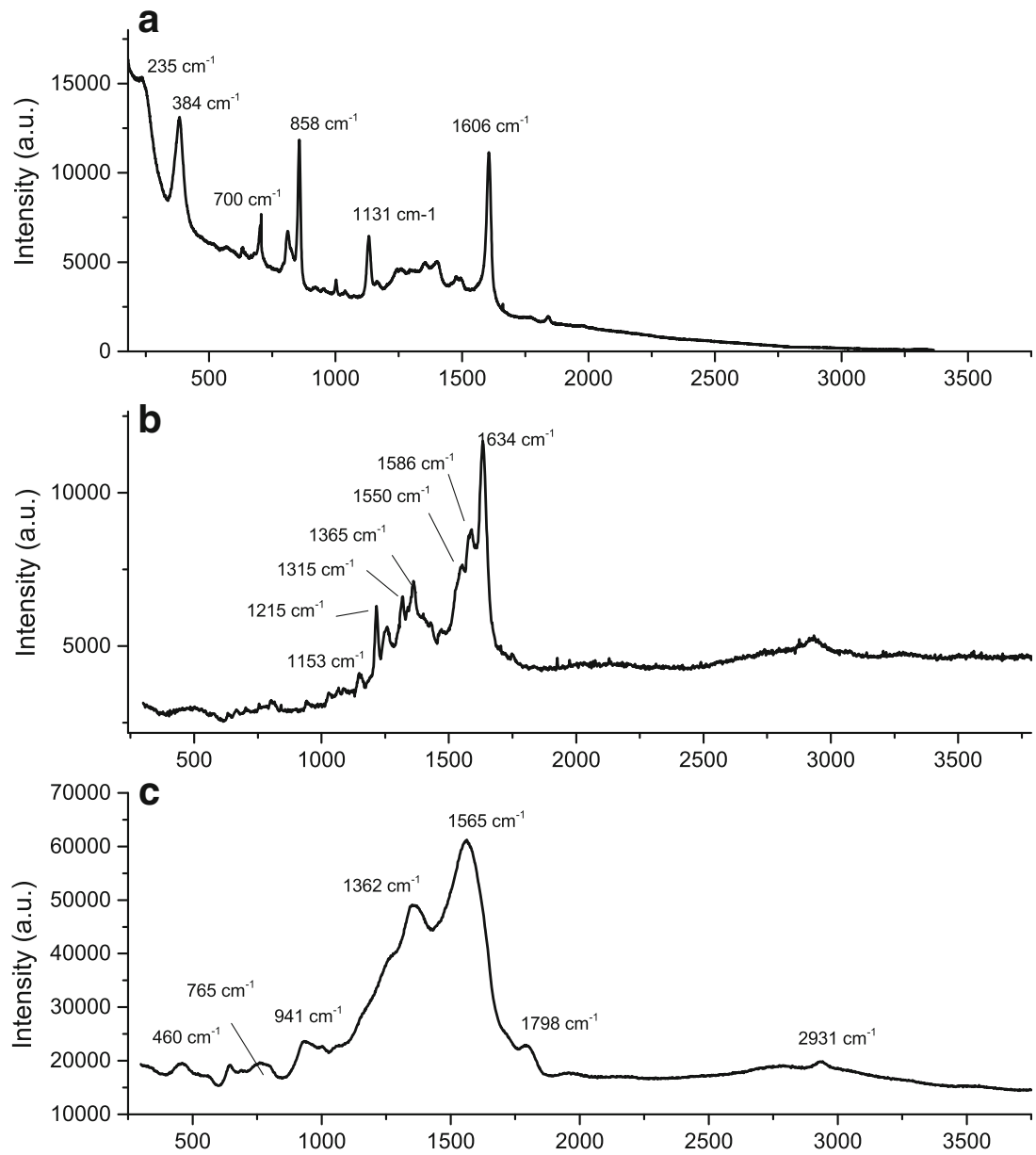

15 to $500 \mathrm{~nm}$ after $20 \mathrm{~min}$. The extensive agglomeration and sedimentation observed for the bare Ag NPs in both AS and ASW (data not shown) disabled any size-quantification by means of NTA and DLS and imply rapid formation of micron-sized agglomerates. Rapid agglomeration of bare Ag NPs in ASW has been reported earlier (Hedberg et al. 2014b; Pind'áková et al. 2017) and is related to the relatively high ionic strength of ASW in this work (Table 1) which shields electrostatic forces, combined with the relatively high attractive van der Waals forces for metal NPs (Pradhan et al. 2016). The higher colloidal stability of the Ag NPs in the mouth spray and the skin cream compared with the bare Ag NPs can to some extent be explained by the presence of adsorbed species (e.g., organic compounds, and residues from the skin cream formulation; see Fig. 3) that can provide electrostatic and steric effects that improve their colloidal stability.

The PVP Ag NPs showed little agglomeration in ASW and AS due to the stabilizing effect of the PVP capping agent, as the main peak in the size distribution was centered close to their primary size at approximately $67 \mathrm{~nm}$.

Figure 4 shows the dissolution kinetics for the Ag NPs of the skin cream in ASW and for the Ag NPs of the mouth spray in AS. The particle loading ( $2 \mathrm{mg} \mathrm{Ag} \mathrm{NPs/L)} \mathrm{is} \mathrm{in} \mathrm{the}$ same range as investigated in other studies (Quadros et al. 2013). This particle loading represents a dilution of the content in the consumer products with a factor of approximately 10 for the skin cream and 15 for the mouth spray. The results for mouth spray are intended to have implications on an exposure scenario in which Ag NPs in a spray product release ions and NPs into the saliva, not to mimic conditions of the mouth spray aerosol (Quadros and Marr 2011). The results are compared with the estimated solubility of silver in ASW and AS at equilibrium conditions as calculated using the Medusa software (see Fig. S5 for complete Ag-Cl speciation information).

The results show a fast initial dissolution of the Ag NPs of the mouth spray to levels close to the estimated solubility of silver in AS after $1 \mathrm{~h}$ exposure. The dissolved fraction was significantly lower after $24 \mathrm{~h}$ compared with $1 \mathrm{~h}(p<0.05$, Student's $t$-test), indicative of precipitation of $\mathrm{AgCl}$ that lowers the concentration of ionic silver in solution over time. These observations highlight the importance of considering the $\mathrm{Cl}^{-} / \mathrm{Ag}^{+}$ratio when conducting dissolution experiments of Ag NPs at chloride-rich conditions (Levard et al. 2012; Levard et al. 2013b). It should be noted that the presence of chlorides also can enhance the dissolution of Ag NPs, 
a
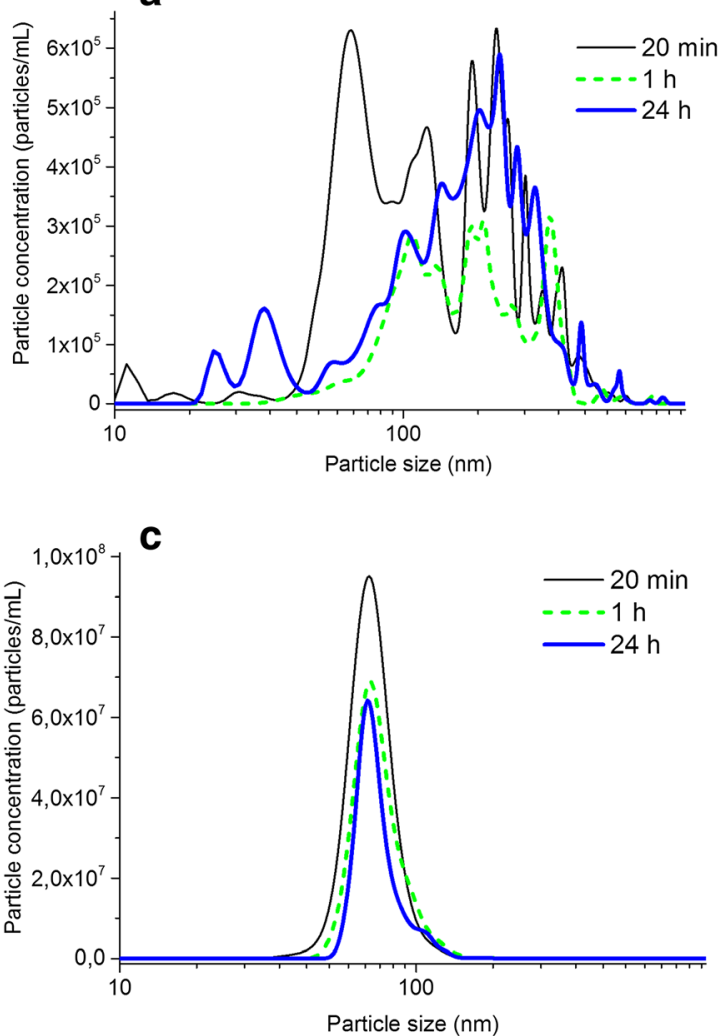

b

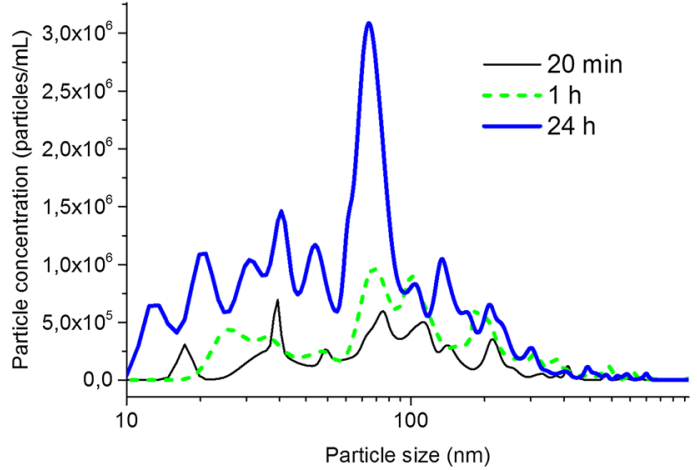

d

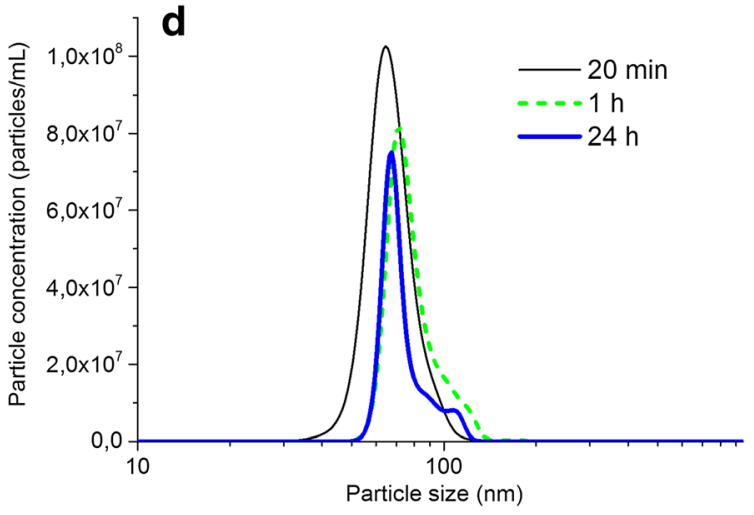

Fig 3 Kinetics of particle size in solution measured by means of NTA, from the Ag NP-containing mouth spray (a) and PVP-capped Ag NPs (c) in AS, and the Ag NP-containing skin cream (b) and PVP-capped Ag NPs (d) exposed in ASW. The results display mean results of three independent samples

especially at under-saturated conditions (Kent and Vikesland 2011).

Rapid dissolution due to the well-known size effect that result in higher solubility and dissolution rates for particles smaller than $20 \mathrm{~nm}$ could also be the case for the Ag NPs (primary size of $2 \mathrm{~nm}$ ) of the mouth spray in this study (Figs. 1, S2) (Hedberg et al. 2019a; Molleman and Hiemstra
2017). Particle agglomeration has however been shown to reduce this nano-specific effect (Allen et al. 2017; Hedberg et al. 2019a). Agglomeration was evident also in this study (Fig. 3), but since NTA cannot detect particles as small as $2 \mathrm{~nm}$, this opens up for the possibility that the rapid initial dissolution kinetics (Fig. 4) is influenced by these small NPs. The presence of surface compounds on the Ag NPs in
Fig. 4 Dissolution kinetics of the Ag NPs of the skin cream in ASW and of the Ag NPs of the mouth spray in AS. The estimated solubility (Medusa software) of silver at equilibrium conditions in ASW and AS is given as the dashed lines. The results display the mean and standard deviation of three independent samples and the error bars correspond to the standard deviation between these samples. The 0 min time point corresponds to the amount of ionic silver determined in the stock solution of the mouth spray. No measurements were possible of the corresponding amount of ionic silver for the skin cream prior to exposure

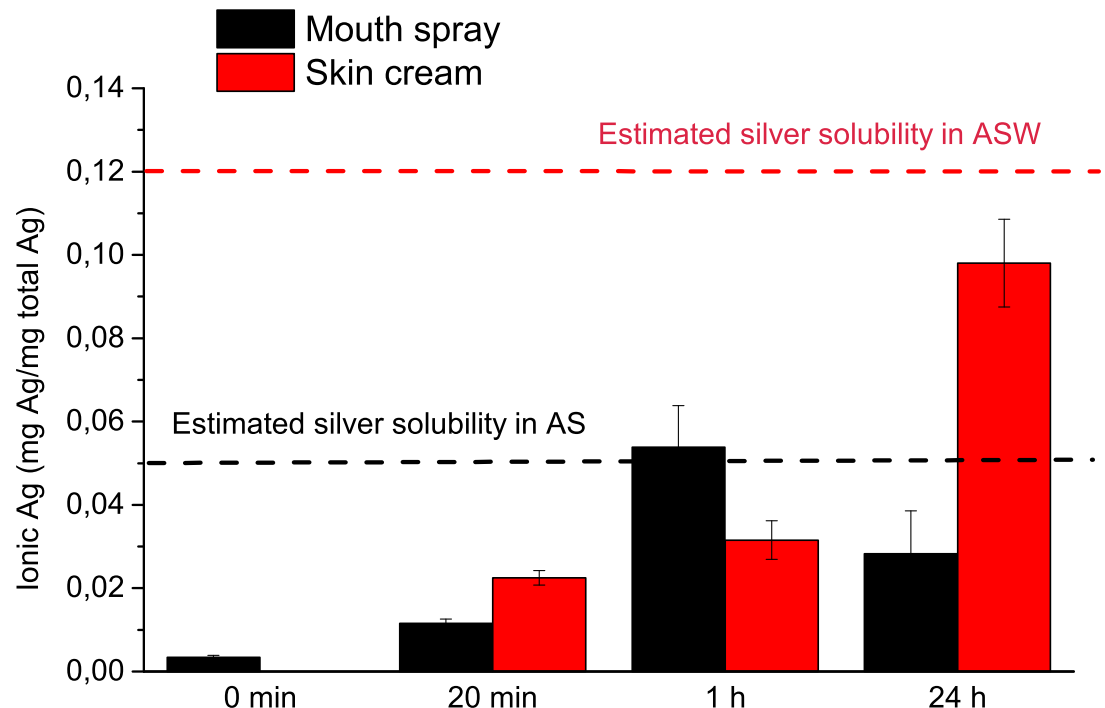




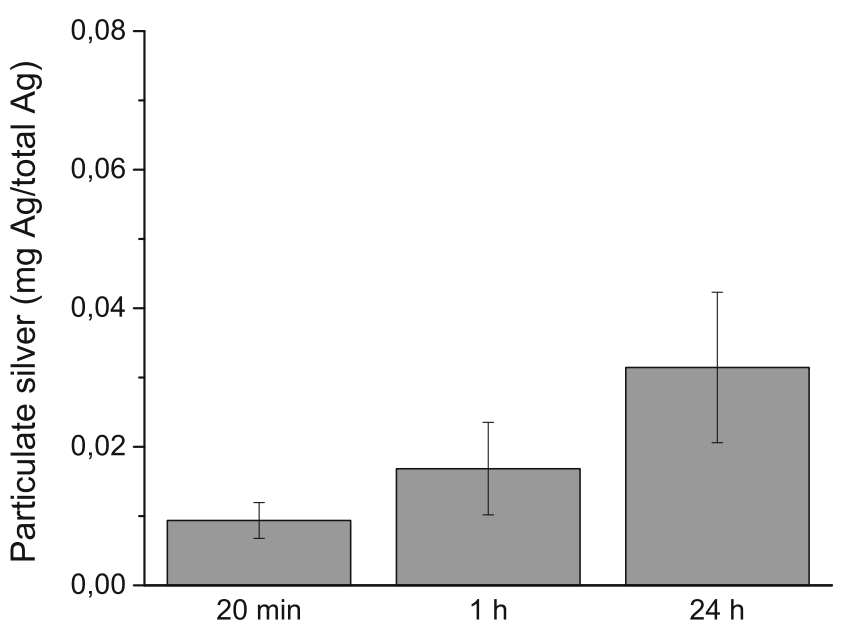

Fig. 5 Kinetics of the release of silver as particles (sized $>20 \mathrm{~nm}$ ) from the Ag NP-containing skin cream exposed in ASW for $20 \mathrm{~min}, 1 \mathrm{~h}$, and $24 \mathrm{~h}$. The results reflect mean values and standard deviation of three independent samples

the mouth spray prior to immersion in AS (Table 1) will also influence the dissolution kinetics (Radwan et al. 2019).

The fraction of silver released as particles from the skin cream into ASW is presented in Fig. 5, defined as the fraction of silver retained by the 20 -nm pore size membrane (see experimental section). The results show a gradual increase of released silver as particles up to $24 \mathrm{~h} \mathrm{(3 \%} \mathrm{of} \mathrm{the} \mathrm{total} \mathrm{amount}$ of $\mathrm{Ag}$ ).

The total amount of released silver (as particles and ions) from the skin cream exposed for $1 \mathrm{~h}$ in ASW equals approximately $1 \mathrm{mg} \mathrm{Ag} / \mathrm{kg}$ product (for a mass to solution ratio of 1:20). This amount is within the range reported by Quadros et al. (0.14-18.5 mg Ag/ $\mathrm{kg}$ ) for a variety of Ag NP-containing products tested in ASW, even though that study was performed using a mass to solution ratio of 1:50 and a time period $2 \mathrm{~h}$ (Quadros et al. 2013). Considering that the skin cream only released ca. 3\% of its Ag NPs into solution (Fig. 5), the amount of ionic silver in solution was high ( $10 \%$ of the total silver content). As discussed above, the presence of the smallsized primary particles within the skin cream could possibly explain the relatively high level of ionic silver (Hedberg et al. 2019b). Also, it is possible that adsorbed organic matter could reduce the chemical stability of the Ag NPs (Molleman and Hiemstra 2017). Radwan et al. furthermore reported that constituents of the consumer product could influence the dissolution kinetics, although the mechanistic understanding is still unknown (Radwan et al. 2019).

In all, the results clearly show that most of the Ag NPs in the mouth spray and the skin cream would remain as NPs even after $24 \mathrm{~h}$ exposure in AS and ASW as less than 10\% of the NPs had dissolved within this time frame. It is anticipated that further transformations of the Ag NPs will take place if transported via, for example, the graywater to the wastewater treatment plant (Hedberg et al. 2014a; Kaegi et al. 2011; Khaksar et al. 2019b), by interactions with other ligands such as sulfides (Levard et al. 2011), and as a result in coating degradation over time (Kirschling et al. 2011).

Table 3 summarizes comparisons between the Ag release from products in this work with other investigated products in AS and ASW.

There are some differences in the reported compositions of artificial sweat and saliva, which makes the comparisons with literature somewhat preliminary. We can note that one other investigations for Ag NPs in artificial sweat used higher $\mathrm{NaCl}$ concentrations $(10.8 \mathrm{~g} / \mathrm{L}$ instead of $5 \mathrm{~g} / \mathrm{L}$ ) (Quadros et al. 2013) which could induce more release of silver compared with this work.

The bare Ag NPs agglomerated more than the NPs of the mouth spray and skin cream, and particle size can largely affect the extent of dissolution (Hedberg et al. 2019b). The

Table 3 Comparisons of release of Ag from consumer products containing Ag NPs. The Ag release from this work corresponds to the release after $24 \mathrm{~h}$

\begin{tabular}{|c|c|c|c|c|c|}
\hline Product & $\begin{array}{l}\text { Ag NP content in product } \\
\text { (mg Ag/kg product) }\end{array}$ & $\begin{array}{l}\text { Ag NP size in } \\
\text { product }(\mathrm{nm})\end{array}$ & $\begin{array}{l}\text { Solution for Ag } \\
\text { release test }\end{array}$ & $\begin{array}{l}\text { Total Ag release } \\
\text { (mg Ag/kg product) }\end{array}$ & Reference \\
\hline Skin cream & $24.1 \pm 0.4$ & $15-25$ & Artificial saliva & $\begin{array}{l}0.3 \pm 0.1 \text { (ionic silver } \\
\quad \text { release) }\end{array}$ & This work \\
\hline Baby blanket & $109.8 \pm 4.1$ & $30-100$ & Artificial saliva & $1.2 \pm 0.1$ & $\begin{array}{l}\text { Quadros et al. 2013) (Tulve } \\
\text { et al. 2015) }\end{array}$ \\
\hline $\begin{array}{l}\text { Plush toy: } \\
\text { interior foam }\end{array}$ & $48.2 \pm 5.0$ & 20 & Artificial saliva & $1.77 \pm 0.03$ & $\begin{array}{l}\text { Quadros et al. 2013) (Tulve } \\
\text { et al. 2015) }\end{array}$ \\
\hline $\begin{array}{l}\text { Plush toy: } \\
\text { interior foam }\end{array}$ & $48.2 \pm 5.0$ & 20 & Artificial saliva & $1.77 \pm 0.03$ & $\begin{array}{l}\text { Quadros et al. 2013) (Tulve } \\
\text { et al. 2015) }\end{array}$ \\
\hline Mouth spray & $31.2 \pm 0.3$ & $2-20$ & Artificial sweat & $1 \pm 0.2$ & This work \\
\hline Baby blanket & $109.8 \pm 4.1$ & $30-100$ & Artificial sweat & $4.8 \pm 0.3$ & $\begin{array}{l}\text { (Quadros et al. 2013; Tulve } \\
\text { et al. 2015) }\end{array}$ \\
\hline $\begin{array}{l}\text { Plush toy: } \\
\text { interior foam }\end{array}$ & $48.2 \pm 5.0$ & 20 & Artificial sweat & $18.5 \pm 1.1$ & $\begin{array}{l}\text { Quadros et al. 2013) (Tulve } \\
\text { et al. 2015) }\end{array}$ \\
\hline Different fabrics & $36.2-425.2$ & $200-500$ & Artificial sweat & $15.5-322$ & (Kulthong et al. 2010) \\
\hline
\end{tabular}


next section explores if the geometric surface area is a way forward to compare dissolution data of differently sized NPs of varying characteristics in consumer products.

\section{Prospects of using geometric surface area to compare dissolution data of NPs in consumer products of varying characteristics}

The following discussion is based on using the geometric surface area of the NPs for normalization of dissolution to explore the possibility to improve comparisons and readacross of Ag NP dissolution data. The geometric surface area is here defined as the area calculated from the primary size determined from electron microscopy imaging prior to any exposure (e.g., Fig. 1).

The wide range of primary Ag NP sizes, as previously reported for different consumer products (Benn and Westerhoff 2008; Quadros et al. 2013; Tulve et al. 2015), makes it difficult to select which sizes of bare Ag NPs that could be used as models for Ag NPs in consumer products. Dissolution/transformation data of bare Ag NPs may further not always be a good proxy for the short-term behavior of $\mathrm{Ag}$ NPs in consumer products. Acute toxic potency of Ag NPs has, for example, been shown to at least to some extent be connected to both particles and to released amounts of ionic silver (Zhang et al. 2016). The results presented in the following are intended to be used as a starting point for further investigations with the aim to find model systems applicable to assess transformation/dissolution scenarios of $\mathrm{Ag}$ NPs in consumer products.

Figure 6 shows dissolution data normalized to the geometric surface area of the Ag NPs in mouth spray skin cream, PVP-capped Ag NPs, and bare Ag NPs. Normalization with geometric surface area to some extent evens out the dissolution results for the Ag NPs in the skin cream, the bare Ag NPs, and the PVP-capped Ag NPs in ASW for the time periods longer than $1 \mathrm{~h}$. The relatively small differences in the normalized dissolution results imply a greater effect of surface area on the dissolution kinetics compared with, for example, differences in primary size that may lead to faster dissolution for particles sized less than $20 \mathrm{~nm}$ (Hedberg et al. 2019b) and effects of adsorbed surface species or capping agents such as in the case of the PVP-capped Ag NPs.

Conversely, normalized dissolution data from the exposure in AS (Fig. 6b) showed large and significant differences for most of the investigated time points. This may be a consequence of released silver levels in solution being close to the saturation level in the case of the Ag NPs from the skin cream (Fig. 4). This saturation can influence the release kinetics (Kuech et al. 2016) and thus make them less comparable to the dissolution of both bare and PVP-capped Ag NPs.

The smaller particle size of the Ag NPs in the consumer products compared with the pristine can in general lead to faster dissolution rates (Kuech et al. 2016). The agglomeration (Fig. 3) will however make this effect smaller and make the properties (e.g., corrosion potentials) similar to larger-sized NPs (Allen et al. 2017).

Figure 7 shows the extent of dissolution of Ag NPs vs. geometric surface area after $24 \mathrm{~h}$ in pure water, AS, and ASW for different Ag NPs, including results of this study and literature findings (Radwan et al. 2019). The Ag NPs presented in Fig. 7 reflect very different characteristics, and they were exposed in different solutions, all of which will have an impact on dissolution process (Hedberg et al. 2019b). Nonetheless, the results show possibly quasi-linear behaviors (although there are too few data points), similar as the clear trend with increased dissolution with increased surface area evident from the results of Radwan et al. on different Ag NPs (bare and in consumer products) (Radwan et al. 2019).
Fig. 6 Release of ionic silver from Ag NPs (after 0 min, 20 min, $1 \mathrm{~h}$, and $24 \mathrm{~h}$ normalized to the geometric surface area. a Ag NPs in skin cream, bare Ag NPs, and PVP-capped Ag NPs in ASW. b Ag NPs in mouth spray, bare Ag NPs, and PVP-capped Ag NPs in AS. The stars indicate significant differences, Student's $t$-test, $p>$ 0.05
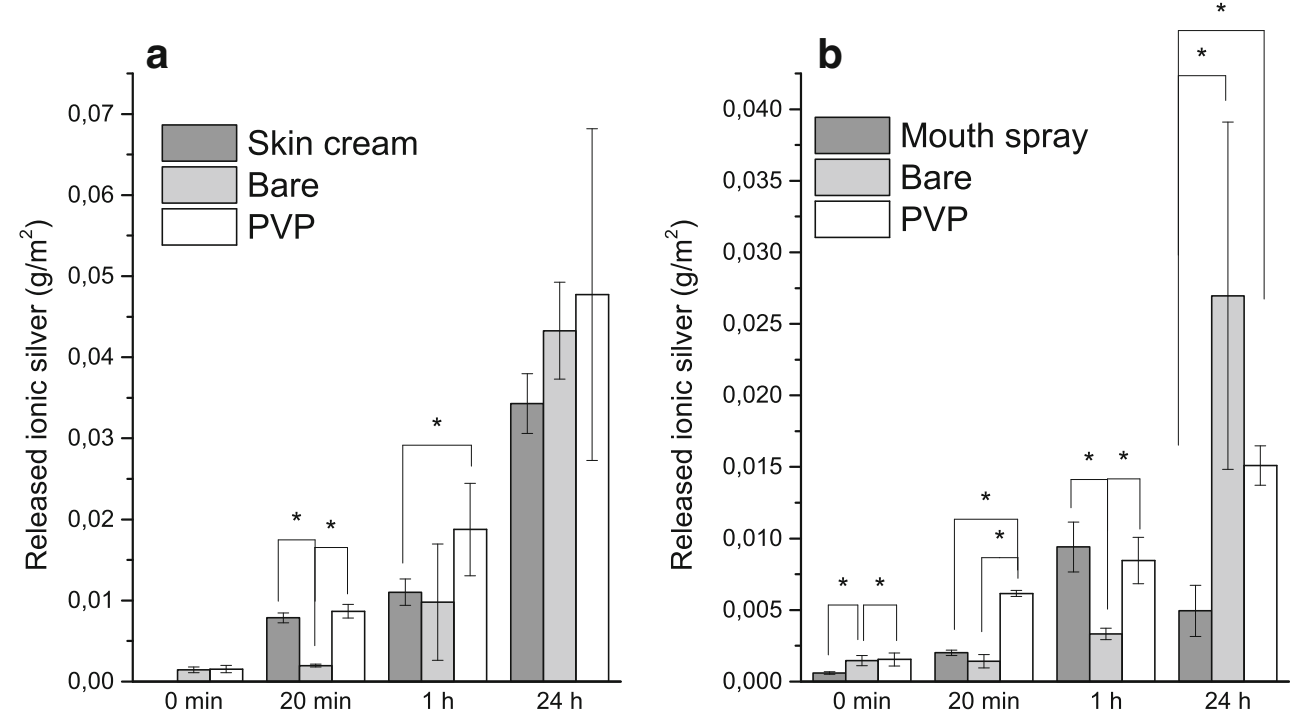
Fig. 7 Dissolution (released ionic silver) after 24-h exposure in AS (filled triangles), ASW (filled squares), and pure water (open circles). Data from Radwan et al. is included for different kinds of Ag NPs (stars) (Radwan et al. 2019). The surface area reflects the total geometric surface area of particles in each experiment calculated from electron microscopy imaging of particle sizes prior to exposure

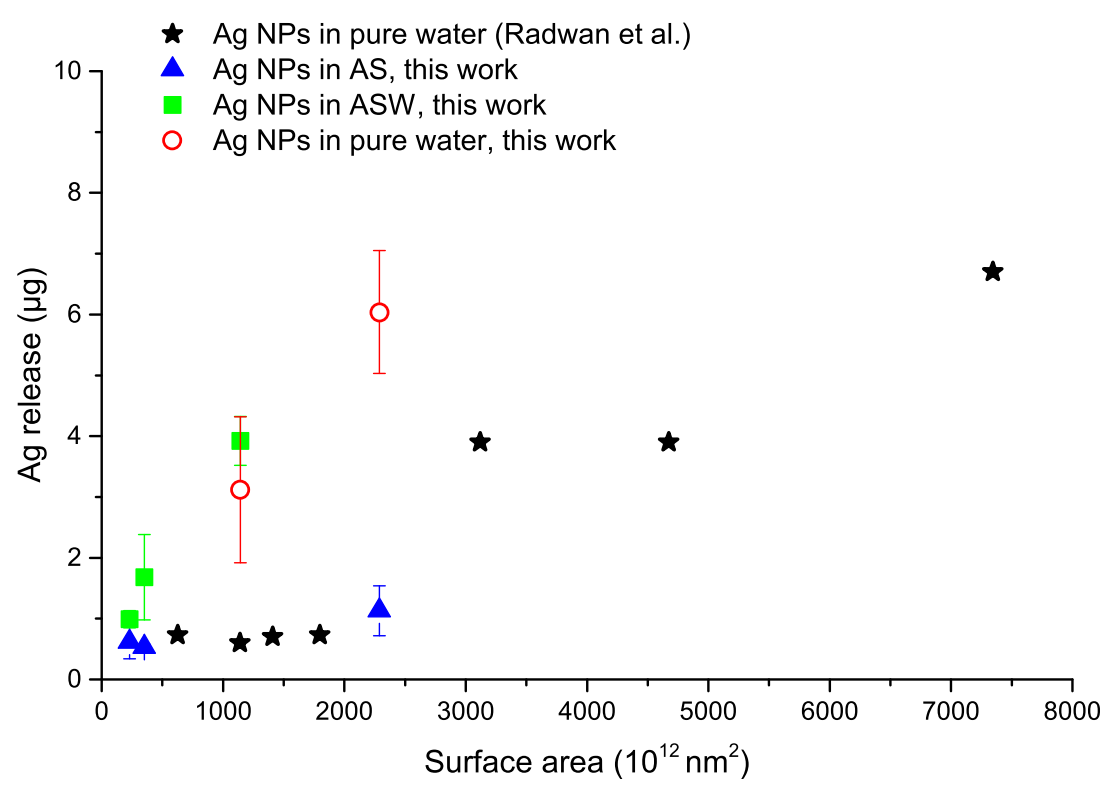

Based on the results in Fig. 7, there are somewhat promising prospects of using the geometric area for simplifying the comparison of dissolution data of Ag NPs from different consumer products. This simplified approach however comes with a price in terms of a relatively wide range of dissolution rates for a given solution. This uncertainty is in line with the relatively large ranges of dissolution rates observed for $\mathrm{Ag}$ NPs in freshwater-like media (Hedberg et al. 2019b; Mitrano et al. 2014). Further investigations need to be conducted in order to assess whether there is a clear trend in terms of surface area versus dissolution for different kinds of solutions. This could pave the way for regressions of dissolution rate versus surface area, data that could be used to support modeling and risk assessments of Ag NPs (Caballero-Guzman and Nowack 2016; Mitrano et al. 2015b; Mitrano and Nowack 2017). An even better area for normalization would be the effective surface area in solution (Dale et al., 2017), which is influenced by, for example, fractal dimensions and porosity that influence the dissolution process (He et al. 2013). However, its applicability is limited as it is much more difficult to assess experimentally than the geometric surface area.

\section{Conclusions}

This study investigated the transformations of Ag NPs in mouth spray and skin cream, in artificial sweat and saliva solutions for up to $24 \mathrm{~h}$. Agglomeration was evident in both solutions for the small-sized primary Ag NPs $(<25 \mathrm{~nm})$ resulting in particle agglomerates sized several hundred nanometers. The dissolution of silver was after $24 \mathrm{~h}$ less than $10 \%$ (with only a few percent released as NPs). The results show that Ag NPs in these consumer products to a large extent will remain as NPs also when becoming mobile in saliva and/or sweat.
Data was compiled to explore the use of geometric surface area of Ag NPs based on electron microscopy imaging as a way to compare dissolution data from Ag NPs in consumer products with the behavior of bare Ag NPs as model particles. The results indicate that the normalization of dissolution with the geometric surface area is promising a way forward as a method to group the dissolution characteristics of Ag NPs from different consumer products. Further investigations are still required to unambiguously conclude its applicability and further use in risk assessment.

Acknowledgments The Åforsk foundation is gratefully acknowledged for financial support. Dr. Fredrik Lindberg, Swerim, is acknowledged for performing the TEM measurements. Dr. Gunilla Herting, KTH, is acknowledged for conducting SEM investigations.

Authors' contributions Conceptualization: JH. Formal analysis: ME, AN, AK, JH. Funding acquisition: JH. Investigation: ME, AN, AK, JH. Methodology: ME, AN, AK, JH. Project administration: JH. Supervision: JH, IOW. Validation: ME, AN, AK, JH. Visualization: ME, AN, AK, JH. Writing — original draft: JH. Writing — review and editing: ME, AN, AK, JH, IOW.

Funding Open access funding provided by Royal Institute of Technology. The Åforsk foundation is gratefully acknowledged for financial support.

Data availability The datasets used and/or analyzed during the current study are available from the corresponding author on reasonable request.

\section{Compliance with ethical standards}

Competing interests The authors declare that they have no competing interests. 
Ethics approval and consent to participate Not applicable.

\section{Consent for publication Not applicable.}

Open Access This article is licensed under a Creative Commons Attribution 4.0 International License, which permits use, sharing, adaptation, distribution and reproduction in any medium or format, as long as you give appropriate credit to the original author(s) and the source, provide a link to the Creative Commons licence, and indicate if changes were made. The images or other third party material in this article are included in the article's Creative Commons licence, unless indicated otherwise in a credit line to the material. If material is not included in the article's Creative Commons licence and your intended use is not permitted by statutory regulation or exceeds the permitted use, you will need to obtain permission directly from the copyright holder. To view a copy of this licence, visit http://creativecommons.org/licenses/by/4.0/.

\section{References}

Allen SL, Sharma JN, Zamborini FP (2017) Aggregation-dependent oxidation of metal nanoparticles. J Am Chem Soc 139:12895-12898

Arvidsson R, Molander S, Sandén BA, Hassellöv M (2011) Challenges in exposure modeling of nanoparticles in aquatic environments. Hum Ecol Risk Assess 17:245-262

Benn TM, Westerhoff P (2008) Nanoparticle silver released into water from commercially available sock fabrics. Environ Sci Technol 42: 4133-4139

Benn T, Cavanagh B, Hristovski K, Posner JD, Westerhoff P (2010) The release of nanosilver from consumer products used in the home. J Environ Qual 39:1875-1882

Caballero-Guzman A, Nowack B (2016) A critical review of engineered nanomaterial release data: are current data useful for material flow modeling? Environ Pollut 213:502-517

CEN (2011) Reference test method for release of nickel from all post assemblies which are inserted into pierced parts of the human body and articles intended to come into direct and prolonged contact with the skin vol EN 1811:2011+A1:2015

Coll C, Notter D, Gottschalk F, Sun T, Som C, Nowack B (2016) Probabilistic environmental risk assessment of five nanomaterials (nano-TiO2, nano-Ag, nano-ZnO, CNT, and fullerenes). Nanotoxicology 10:436-444

Cronholm $\mathrm{P}$ et al (2013) Intracellular uptake and toxicity of $\mathrm{Ag}$ and $\mathrm{CuO}$ nanoparticles: a comparison between nanoparticles and their corresponding metal ions. Small 9:970-982

Dale AL, Lowry GV, Casman EA (2017) Accurate and fast numerical algorithms for tracking particle size distributions during nanoparticle aggregation and dissolution. Environ Sci Nano 4:89-104

Gunawan C, Marquis CP, Amal R, Sotiriou GA, Rice SA, Harry EJ (2017) Widespread and indiscriminate nanosilver use: genuine potential for microbial resistance. ACS Nano 11:3438-3445

Hansen SF, Heggelund LR, Besora PR, Mackevica A, Boldrin A, Baun A (2016) Nanoproducts-what is actually available to European consumers? Environ Sci Nano 3:169-180

He D, Bligh MW, Waite TD (2013) Effects of aggregate structure on the dissolution kinetics of citrate-stabilized silver nanoparticles. Environ Sci Technol 47:9148-9156. https://doi.org/10.1021/es400391a

Hedberg J, Lundin M, Lowe T, Blomberg E, Wold S, Odnevall Wallinder I (2012) Interactions between surfactants and silver nanoparticles of varying charge. J Colloid Interface Sci 369:193-201. https://doi.org/ 10.1016/j.jcis.2011.12.004

Hedberg J, Baresel C, Odnevall Wallinder I (2014a) Transport and fate of silver as polymer-stabilised nanoparticles and ions in a pilot wastewater treatment plant, followed by sludge digestion and disposal of sludge/soil mixtures: a case study. J Environ Sci Health A 49:1416-1424

Hedberg J, Skoglund S, Karlsson M-E, Wold S, Odnevall Wallinder I, Hedberg YS (2014b) Sequential studies of silver released from silver nanoparticles in aqueous media simulating sweat, laundry detergent solutions and surface water. Environ Sci Technol 48:7314 7322

Hedberg J, Blomberg E, Odnevall Wallinder I (2019a) In the search for nano-specific effects of dissolution of metallic nanoparticles at freshwater-like conditions-a critical review. Environ Sci Technol 53:4030

Hedberg J, Blomberg E, Odnevall Wallinder I (2019b) In the search for nanospecific effects of dissolution of metallic nanoparticles at freshwater-like conditions: a critical review. Environ Sci Technol 53:4030-4044. https://doi.org/10.1021/acs.est.8b05012

Kaegi R, Voegelin A, Sinnet B, Zuleeg S, Hagendorfer H, Burkhardt M, Siegrist H (2011) Behavior of metallic silver nanoparticles in a pilot wastewater treatment plant. Environ Sci Technol 45:3902-3908. https://doi.org/10.1021/es1041892

Kai S, Chaozhi W, Guangzhi X (1989) Surface enhanced Raman spectra of carbonate, hydrocarbonate, and substituted acetic acids on silver hydrosols. Spectrochim Acta A Mol Biomol Spectrosc 45:10291032

Keller AA, Vosti W, Wang H, Lazareva A (2014) Release of engineered nanomaterials from personal care products throughout their life cycle. J Nanopart Res 16:2489

Kemikalieinspektionen (2015) Förslag om utökad anmälningsplikt för nanomaterial (in Swedish) vol Rapport 10/15

Kent RD, Vikesland PJ (2011) Controlled evaluation of silver nanoparticle dissolution using atomic force microscopy. Environ Sci Technol 46:6977-6984. https://doi.org/10.1021/es203475a

Khaksar M et al (2019a) Chemical characterisation, antibacterial activity, and (nano) silver transformation of commercial personal care products exposed to household greywater. Environ Sci Nano 6:30273038

Khaksar M et al (2019b) Chemical characterisation, antibacterial activity, and (nano)silver transformation of commercial personal care products exposed to household greywater. Environ Sci Nano in press. https://doi.org/10.1039/x0xx00000x

Kirschling TL, Golas PL, Unrine JM, Matyjaszewski K, Gregory KB, Lowry GV, Tilton RD (2011) Microbial bioavailability of covalently bound polymer coatings on model engineered nanomaterials. Environ Sci Technol 45:5253-5259

Koivisto AJ, Jensen ACØ, Kling KI, Nørgaard A, Brinch A, Christensen F, Jensen KA (2017) Quantitative material releases from products and articles containing manufactured nanomaterials: towards a release library. NanoImpact 5:119-132

Kuech TR, Hamers RJ, Pedersen JA (2016) Chemical transformation of metal, metal oxide, and metal chalcogenide nanoparticles in the environment. Wiley, Hoboken

Kulthong K, Srisung S, Boonpavanitchakul K, Kangwansupamonkon W, Maniratanachote R (2010) Determination of silver nanoparticle release from antibacterial fabrics into artificial sweat. Part Fibre Toxicol 7:8. https://doi.org/10.1186/1743-8977-7-8

Levard C, Reinsch BC, Michel FM, Oumahi C, Lowry GV, Brown GE (2011) Sulfidation processes of PVP-coated silver nanoparticles in aqueous solution: impact on dissolution rate. Environ Sci Technol 45:5260-5266. https://doi.org/10.1021/es2007758

Levard C, Hotze EM, Lowry GV, Brown GE (2012) Environmental transformations of silver nanoparticles: impact on stability and toxicity. Environ Sci Technol 46:6900-6914. https://doi.org/10.1021/ es2037405

Levard C, Hotze EM, Colman BP, Dale AL, Truong L, Yang XY, Bone AJ, Brown GE Jr, Tanguay RL, di Giulio RT, Bernhardt ES, Meyer JN, Wiesner MR, Lowry GV (2013a) Sulfidation of silver 
nanoparticles: natural antidote to their toxicity. Environ Sci Technol 47:13440-13448. https://doi.org/10.1021/es403527n

Levard C, Mitra S, Yang T, Jew AD, Badireddy AR, Lowry GV, Brown GE (2013b) Effect of chloride on the dissolution rate of silver nanoparticles and toxicity to E. coli. Environ Sci Technol 47:5738-5745. https://doi.org/10.1021/es400396f

Lin-Vien D, Colthup NB, Fateley WG, Grasselli JG (1991) The handbook of infrared and Raman characteristic frequencies of organic molecules. Elsevier, Amsterdam

Liu C, Leng W, Vikesland PJ (2018) Controlled evaluation of the impacts of surface coatings on silver nanoparticle dissolution rates. Environ Sci Technol 52:2726-2734

Mackevica A, Olsson ME, Hansen SF (2016) Silver nanoparticle release from commercially available plastic food containers into food simulants. J Nanopart Res 18:5

Mackevica A, Olsson ME, Hansen SF (2017) The release of silver nanoparticles from commercial toothbrushes. J Hazard Mater 322:270 275

McQuillan AJ, Hendra PJ, Fleischmann M (1975) Raman spectroscopic investigation of silver electrodes. J Electroanal Chem Interfacial Electrochem 65:933-944. https://doi.org/10.1016/0368-1874(75) 85167-7

Mdluli PS, Sosibo NM, Revaprasadu N, Karamanis P, Leszczynski J (2009) Surface enhanced Raman spectroscopy (SERS) and density functional theory (DFT) study for understanding the regioselective adsorption of pyrrolidinone on the surface of silver and gold colloids. J Mol Struct 935:32-38

Mehrabi K, Nowack B, Arroyo Rojas Dasilva Y, Mitrano DM (2017) Improvements in nanoparticle tracking analysis to measure particle aggregation and mass distribution: a case study on engineered nanomaterial stability in incineration landfill leachates. Environ Sci Technol 51:5611-5621

Mitrano DM, Nowack B (2017) The need for a life-cycle based aging paradigm for nanomaterials: importance of real-world test systems to identify realistic particle transformations. Nanotechnology 28: 072001

Mitrano D, Ranville J, Bednar A, Kazor K, Hering A, Higgins C (2014) Tracking dissolution of silver nanoparticles at environmentally relevant concentrations in laboratory, natural, and processed waters using single particle ICP-MS (spICP-MS). Environ Sci Nano 1: 248-259

Mitrano DM, Arroyo Rojas Dasilva Y, Nowack B (2015a) Effect of variations of washing solution chemistry on nanomaterial physicochemical changes in the laundry cycle. Environ Sci Technol 49: 9665-9673

Mitrano DM, Motellier S, Clavaguera S, Nowack B (2015b) Review of nanomaterial aging and transformations through the life cycle of nano-enhanced products. Environ Int 77:132-147

Mohan S, Princz J, Ormeci B, DeRosa MC (2019) Morphological transformation of silver nanoparticles from commercial products: modeling from product incorporation, Weathering through Use Scenarios, and Leaching into Wastewater. Nanomaterials 9:1258
Molleman B, Hiemstra T (2017) Time, pH, and size dependency of silver nanoparticle dissolution: the road to equilibrium. Environ Sci Nano 4:1314-1327

Moskovits M (2005) Surface-enhanced Raman spectroscopy: a brief retrospective. J Raman Spectrosc 36:485-496. https://doi.org/10.1002/ jrs. 1362

Ngamchuea K, Batchelor-McAuley C, Compton RG (2018) The fate of silver nanoparticles in authentic human saliva. Nanotoxicology 12: 305-311

Oh K-T, Kim K-N (2005) Ion release and cytotoxicity of stainless steel wires. Eur J Orthod 27:533-540

Pind'áková L, Kašpárková V, Kejlová K, Dvořáková M, Krsek D, Jírová D, Kašparová L (2017) Behaviour of silver nanoparticles in simulated saliva and gastrointestinal fluids. Int J Pharm 527:12-20

Pradhan S, Hedberg J, Blomberg E, Wold S, Odnevall Wallinder I (2016) Effect of sonication on particle dispersion, administered dose and metal release of non-functionalized, non-inert metal nanoparticles. J Nanopart Res 18:285

Puigdomenech I (2001) HYDRA MEDUSA: make equilibrium diagrams using sophisticated algorithms (http://www.kemi.kth.se/medusa/). KTH (Royal Institute of Technology), Stockholm, Sweden

Quadros ME, Marr LC (2011) Silver nanoparticles and total aerosols emitted by nanotechnology-related consumer spray products. Environ Sci Technol 45:10713-10719

Quadros ME, Pierson R, Tulve NS, Willis R, Rogers K, Thomas TA, Marr LC (2013) Release of silver from nanotechnology-based consumer products for children. Environ Sci Technol 47:8894-8901. https://doi.org/10.1021/es4015844

Radwan IM, Gitipour A, Potter PM, Dionysiou DD, Al-Abed SR (2019) Dissolution of silver nanoparticles in colloidal consumer products: effects of particle size and capping agent. J Nanopart Res 21:155155

Skoglund S, Hedberg J, Yunda E, Godymchuk A, Blomberg E, Odnevall Wallinder I (2017) Difficulties and flaws in performing accurate determinations of zeta potentials of metal nanoparticles in complex solutions-Four case studies. PLoS One 12:e0181735

Tulve NS et al (2015) Characterization of silver nanoparticles in selected consumer products and its relevance for predicting children's potential exposures. Int J Hyg Environ Health 218:345-357

Vance ME, Kuiken T, Vejerano EP, McGinnis SP, Hochella MF Jr, Rejeski D, Hull MS (2015) Nanotechnology in the real world: redeveloping the nanomaterial consumer products inventory. Beilstein J Nanotechnol 6:1769-1780

Zhang C, Hu Z, Deng B (2016) Silver nanoparticles in aquatic environments: physiochemical behavior and antimicrobial mechanisms. Water Res 88:403-427

Publisher's note Springer Nature remains neutral with regard to jurisdictional claims in published maps and institutional affiliations. 